\title{
Butorphanol prevents morphine-induced pruritus without increasing pain and other side effects: a systematic review of randomized controlled trials
}

\section{Le butorphanol prévient le prurit induit par la morphine sans augmentation de la douleur et des autres effets secondaires: une revue méthodique des études randomisées contrôlées}

\author{
Bo-Xiang Du, MSc $\cdot$ Zhe-Ming Song, MSc $\cdot$ Kai Wang, BSc $\cdot$ Hao Zhang, MD $\cdot$ \\ Feng-Ying Xu, BSc $\cdot$ Zui Zou, MD $\cdot$ Xue-Yin Shi, MD
}

Received: 24 December 2012/Accepted: 17 June 2013/Published online: 28 June 2013

(C) Canadian Anesthesiologists' Society 2013

\begin{abstract}
Purpose Pruritus is a frequent adverse event after administration of morphine. Butorphanol has been used to prevent morphine-induced pruritus, but its efficacy is still controversial. The aim of this systematic review was to evaluate the efficacy of using butorphanol to prevent morphine-induced pruritus.

Source We searched PubMed, Cochrane Library, EMBASE, and China's BioMedical Disc for full reports of randomized controlled trials that compared the use of butorphanol with either placebo or no treatment for preventing morphine-
\end{abstract}

Bo-Xiang Du and Zhe-Ming Song contributed equally to this work. Xue-Yin Shi is the primary corresponding author.

Author contributions Bo-Xiang Du, Zhe-Ming Song, Zui Zou, and Hao Zhang helped design the study. Bo-Xiang Du, Zhe-Ming Song, Zui Zou, and Xue-Yin Shi helped conduct the study. Bo-Xiang Du, Zhe-Ming Song, Zui Zou, and Feng-Ying Xu helped analyze the data and write the manuscript. Bo-Xiang Du, Zhe-Ming Song, Zui Zou, Kai Wang, Hao Zhang, Feng-Ying Xu, and Xue-Yin Shi have seen the original study data and reviewed the analysis of the data. Kai Wang helped with literature collection.

B.-X. Du, MSc · Z.-M. Song, MSc · H. Zhang, MD .

F.-Y. Xu, BSc · Z. Zou, MD $(\bowtie) \cdot X .-Y$. Shi, MD $(\bowtie)$

Department of Anesthesiology, Changzheng Hospital, Second

Military Medical University, 415 Fengyang Road,

Shanghai, PR China

e-mail: zouzui1980@yahoo.com.cn

X.-Y. Shi, MD

e-mail: xueyinshi@yahoo.com

K. Wang, BSc

Department of Anesthesiology, First Affiliated Hospital of

Xuzhou Medical College, Xuzhou, Jiangsu Province, PR China induced pruritus. The number of patients experiencing pruritus or other side effects was analyzed using relative risk $(R R)$ with $95 \%$ confidence intervals $(\mathrm{CI})$.

Principal findings Sixteen trials (795 patients) were analyzed. Continuous intravenous and epidural butorphanol reduced pruritus with $R R 0.22(95 \%$ CI 0.10 to 0.45$)$ and $R R$ 0.24 (95\% CI 0.16 to 0.36), respectively. Use of epidural butorphanol decreased the number of patients requesting rescue treatment for pruritus (RR 0.57; 95\% CI 0.41 to 0.81 ). Butorphanol decreased postoperative pain intensity at four, eight, and $12 \mathrm{hr}$ with standardized mean differences of -0.29 (95\% CI -0.52 to -0.05$)$, -0.30 (95\% CI -0.56 to -0.04 ), and -0.23 (95\% CI -0.46 to -0.01$)$, respectively. Epidural but not intravenous butorphanol reduced postoperative nausea and vomiting (PONV) (RR 0.35; 95\% CI 0.19 to 0.66). Butorphanol did not increase respiratory depression (RR 0.71; 95\% CI0.31 to 1.63), somnolence (RR 0.71; 95\% CI 0.22 to 2.37), or dizziness (RR 2.45; 95\% CI 0.35 to 17.14). Conclusion Butorphanol administered with morphine may be an effective strategy for preventing morphineinduced pruritus as it decreases pain intensity and PONV without increasing other side effects. Thus, it can be recommended for preventing morphine-induced pruritus during the perioperative period.

\footnotetext{
Résumé

Objectif Le prurit est un effet secondaire néfaste fréquent après l'administration de morphine. Le butorphanol a été utilisé pour prévenir le prurit induit par la morphine, mais son efficacité est encore controversée. L'objectif de cette revue méthodique était d'évaluer l'efficacité du butorphanol pour prévenir le prurit induit par la morphine.
} 
Source Nous avons effectué une recherche dans les bases de données PubMed, Cochrane Library, EMBASE, et le BioMedical Disc chinois pour en extraire les comptes rendus d'études randomisées contrôlées comparant l'utilisation de butorphanol vs. un placebo ou aucun traitement pour prévenir le prurit induit par la morphine. Le nombre de patients souffrant de prurit ou d'autres effets secondaires a été analysé en étudiant le risque relatif $(R R)$ avec des intervalles de confiance (IC) de $95 \%$.

Constatations principales Au total, 16 études (795 patients) ont été analysées. Le butorphanol en administration intraveineuse continue et en péridurale a réduit le prurit avec un RR de 0,22 (IC $95 \% 0,10$ à 0,45$)$ et un $R R$ de 0,24 (IC $95 \%$ 0,16 à 0,36), respectivement. L'utilisation de butorphanol a réduit le nombre de patients nécessitant un traitement de secours pour le prurit (RR 0,57; IC $95 \%$ 0,41 à 0,81). Le butorphanol a réduit l'intensité de la douleur postopératoire à quatre, huit et 12 $h$ avec des différences moyennes normalisées de -0,19 (IC $95 \%-0,52$ à-0,05), -0,30 (IC $95 \%-0,56 \grave{a}-0,04)$ et $-0,23$ (IC $95 \%-0,46$ à $-0,01)$, respectivement. Le butorphanol administré en péridurale mais non en intraveineuse a réduit les nausées et vomissements postopératoires (NVPO) (RR 0,35; IC $95 \%$ 0,19 à 0,66). Le butorphanol n'a pas augmenté la dépression respiratoire (RR 0,71; IC $95 \%$ 0,31 à 1,63), la somnolence (RR 0,71; IC $95 \%$ 0,22 à 2,37), ou les étourdissements (RR 2,45; IC $95 \%$ 0,35 à 17,14).

Conclusion Le butorphanol administré conjointement à la morphine pourrait constituer une stratégie efficace pour prévenir le prurit induit par la morphine, étant donné qu'il réduit l'intensité de la douleur et les NVPO sans augmenter les autres effets secondaires. Dès lors, on peut recommander son utilisation pour la prévention du prurit induit par la morphine pendant la période périopératoire.

The administration of opioids is one of the most common analgesic methods during and after a surgical procedure. Morphine is a frequently used opioid that can provide effective perioperative analgesia; however, it is often accompanied by a wide variety of troublesome side effects. ${ }^{1}$ Pruritus is an major adverse effect after morphine administration with a reported incidence of 30$100 \%$ following neuraxial administration of opioids ${ }^{2}$ and $10-50 \%$ following intravenous administration. ${ }^{3}$ Currently, the exact mechanism of morphine-induced pruritus is unclear.

Butorphanol, a synthetic opioid that exhibits partial agonist and antagonist activity at the $\mu$-opioid receptors and agonist activity at the $\kappa$-opioid receptors ${ }^{4}$ has been approved by the United States Food and Drug Administration for the management of pain. Butorphanol has been used in clinical practice for musculoskeletal pain, migraine headaches, ${ }^{5}$ and perioperative analgesia and has shown a good safety profile when added to a perioperative regimen. ${ }^{6,7}$ Advantages of butorphanol include few adverse effects, low addiction potential, and low toxicity. ${ }^{8}$ The most frequently reported adverse effects of butorphanol include somnolence, dizziness, and nausea or vomiting. ${ }^{5}$

Due to its activity on the $\mu$ - and $\kappa$-opioid receptors, butorphanol could be an effective prophylactic treatment for morphine-induced pruritus while administered with morphine; however, there are conflicting results regarding the efficacy of this approach. It remains unclear whether the addition of butorphanol could influence the analgesia effect of morphine or induce other side effects.

The purpose of this systematic review was to evaluate the efficacy and safety of butorphanol in preventing morphine-induced pruritus in perioperative analgesia.

\section{Methods}

This systematic review was conducted according to the PRISMA recommendations for improving the quality of meta-analysis. ${ }^{9}$

Eligibility criteria

We conducted a comprehensive search for all published reports of randomized controlled trials testing the effect of prophylactic systemic (intravenous, epidural, intramuscular, subcutaneous, oral, and transdermal) administration of butorphanol compared with placebo or no treatment. Both groups were in combination with morphine for perioperative analgesia. The relevant studies reported data regarding morphine-induced pruritus.

Exclusion criteria included trials studying the treatment of established pruritus with butorphanol and studies combining butorphanol with other anti-pruritus agents.

Information sources

We searched PubMed, Cochrane Library, EMBASE and China's BioMedical Disc without restriction on the year or language of the published articles. The following keywords were used in our search: pruritus or itching, butorphanol, morphine, operative or surgical, postoperative or postsurgical, anesthesia, analgesia, randomized or randomised, and controlled. The last search was conducted in November 2012. The reference lists of the original research, reviews, letters to the editor, and case 
reports were also scanned to identify studies not included in the computerized databases.

\section{Study selection}

Two authors (D.B.X. and S.Z.M.) independently reviewed all articles identified for inclusion through the literature search. Any disagreement was adjudicated among all authors.

\section{Data extraction process}

A computerized spreadsheet (Microsoft Excel 2007) was created for data extraction. Two authors (D.B.X. and S.Z.M.) independently extracted relevant information from the original reports. Any disagreement was solved by decision among all authors.

\section{Data items}

The primary end point of efficacy was the incidence of pruritus with butorphanol compared with control. Itching was considered equivalent to pruritus. The number of patients requesting rescue treatment for pruritus was another end point.

To record pain intensity, a postoperative visual analogue scale (VAS) ranging from $0 \mathrm{~mm}$ (no pain) to $100 \mathrm{~mm}$ (worst pain) was extracted as means with standard deviations. Data were also extracted for other postoperative adverse events associated with morphine and butorphanol, e.g., postoperative nausea and vomiting (PONV), respiratory depression, dizziness, and somnolence.

Furthermore, the extracted information included the regimens of morphine and butorphanol, the number of patients in the experimental and control groups, and the type of surgery.

\section{Risk of bias in individual studies}

Two authors (D.B.X. and S.Z.M.) independently assessed the risk of bias in the included studies according to the guidelines recommended by the Cochrane collaboration. ${ }^{10}$ The risk of bias was assessed in six categories, including sequence generation, allocation, blinding, incomplete outcome data, selective outcome reporting, and other sources of bias. Each domain was judged in accordance with three rulings: Yes indicated a low risk of bias; No indicated a high risk of bias; and Unclear indicated an unclear risk of bias. Any disagreement was settled through discussion with a third author (W.K.).

\section{Statistical analysis}

Relative risk (RR) with $95 \%$ confidence interval (CI) was computed for dichotomous outcomes extracted as the presence or absence of an effect. A formal heterogeneity test was performed, and a $P$ value was used to assess heterogeneity among trials. If $P$ value was $<0.1$, the hypothesis of homogeneity was rejected and the following techniques were used: 1) subgroup analysis; 2) a random effects model; and 3) sensitivity analysis by excluding the trials that potentially biased the results. For the VAS pain score, a standardized mean difference (SMD) with $95 \% \mathrm{CI}$ was computed.

The potential publication bias regarding our primary variable RR was evaluated by Egger's test and a funnel plot. In Egger's tests, $P<0.05$ implies an existing publication bias. A fail-safe number was calculated to assess the stability of our results if publication bias was found.

Statistical analysis was conducted using Review Manager Version 5.0.24 (Cochrane Collaboration, Oxford, UK) and Stata $^{\circledR}$ v10.0 (Stata Corp, College Station, TX, USA) software.

\section{Quality assessment of this review}

The AMSTAR rating scale, a measurement tool to assess the methodological quality of systematic reviews, was used to assess the quality of this review. The AMSTAR criteria $^{11}$ include: 1) a priori design; 2) duplicate study selection and data extraction; 3) comprehensive literature search; 4) inclusive publication status; 5) included/ excluded studies provided; 6) characteristics of included studies provided; 7) quality assessment of studies; 8) study quality used appropriately in formulating conclusions; 9) appropriate methods used to combine studies; 10) publication bias assessed; and 11) conflict of interest stated.

\section{Results}

Study selection

According to the search strategy, 93 potentially relevant trials were retrieved, and 77 trials were subsequently excluded (Fig. 1). Ultimately, 16 valid trials were analyzed with data for 795 patients, 452 of whom received butorphanol (Table 1). ${ }^{12-27}$ Four of these trials involved children $<18$ years of age. ${ }^{21-24}$

The methodological quality of the included studies

Ten of the 16 included trials ${ }^{13,18,20-27}$ provided a sequence generation for randomization. Most trials did not show adequate information about the allocation concealment; 11 studies $^{12,13,18,20-27}$ were double-blinded. All studies had either no incomplete outcome or addressed the incomplete 
Fig. 1 Flow chart of systematic research. $\mathrm{RCT}=$ randomized controlled trial

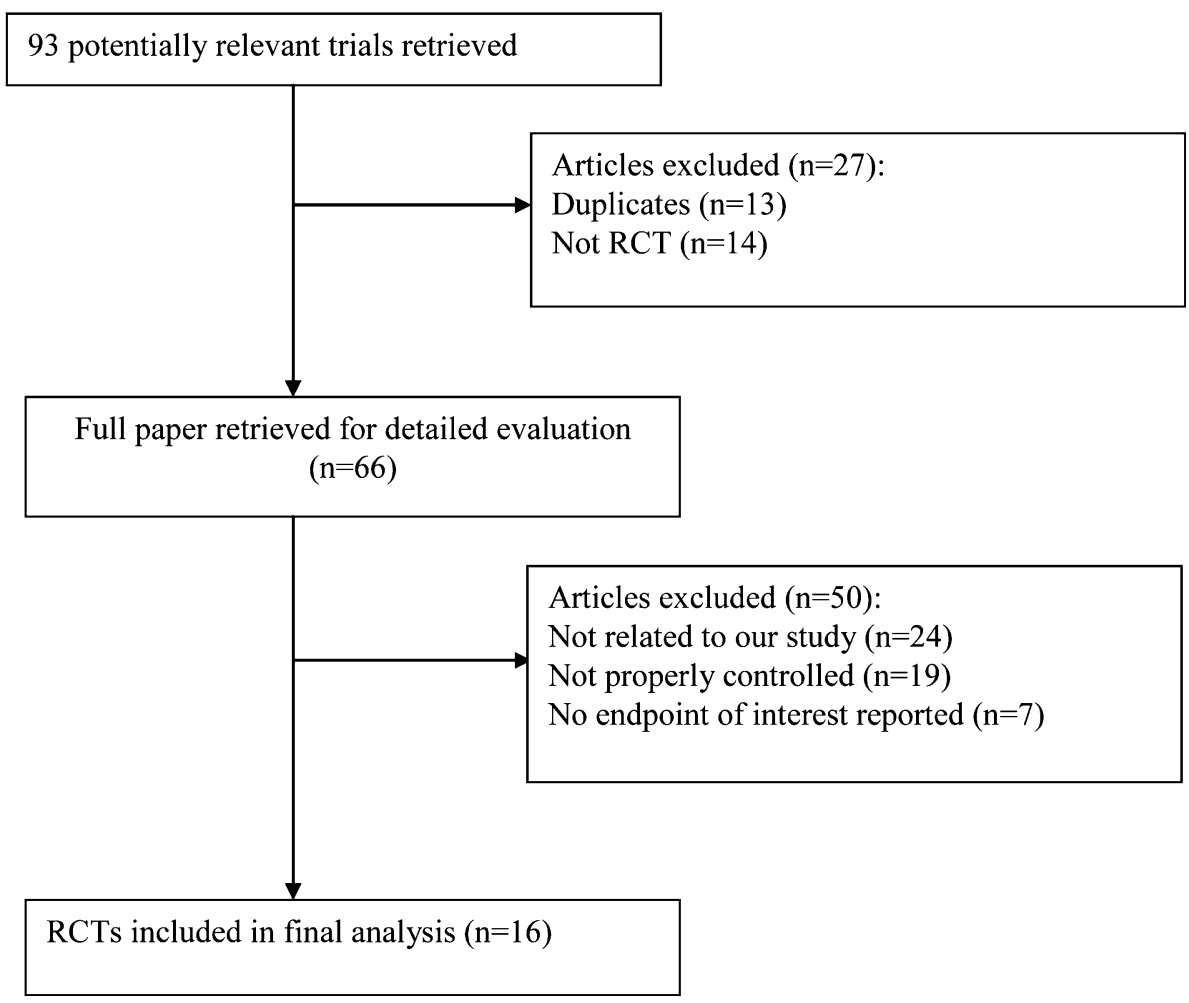

outcome. Only one study ${ }^{17}$ did not report all the end points mentioned in the Methods section. We failed to determine whether one pilot study ${ }^{20}$ was free from other sources of bias. An overview of the risk of bias is summarized in Fig. 2.

\section{Study characteristics}

The characteristics of all included trials are shown in Table 1. The eligible studies were published from 1991-2012 in three languages: English (nine studies), Chinese (six studies), ${ }^{12,14-17,19}$ and Japanese (one study). ${ }^{18}$ Sample sizes ranged from 14-91 patients. Surgery included Cesarean delivery (seven studies), hysterectomy (two studies), radical resection of rectal carcinoma (one study), dorsal rhizotomy (one study), and not specified or a composite of different surgeries (five studies). The observation period of the included trials ranged from $24-75 \mathrm{hr}$, with one ${ }^{17}$ not reported.

The incidence of pruritus

The primary outcome in 11 trials was the incidence of pruritus. $^{12-19,22-24}$ On average, $51.4 \%$ (132/257) of patients receiving morphine without butorphanol experienced pruritus. Trials were assigned into different subgroups according to the routes of butorphanol administration, but it was impossible to test the dose-response relationship of butorphanol because few trials used the same dose.
In eight trials, epidural butorphanol was administered to prevent pruritus and an estimation of its efficacy was performed (Fig. 3). The combined data indicated a significantly lower incidence of pruritus in the butorphanol groups (RR 0.24; 95\% CI 0.16 to 0.36) (Fig. 3). For sensitivity analysis, a re-estimation was performed after excluding 1) one study $^{23}$ with a group size of $<$ ten patients, and a significant difference was still found (RR 0.25 ; 95\% CI 0.16 to 0.37 ); and 2) one trial ${ }^{17}$ with high risk of bias, and the difference was still significant (RR 0.23 ; 95\% CI 0.15 to 0.35 ). Trials with epidural butorphanol were further assigned into two subgroups according to the age of the participants. The RR of the children subgroup suggested that epidural butorphanol was significantly more effective than placebo (RR 0.35; 95\% CI 0.16 to 0.80). Five trials involved adults receiving epidural butorphanol, ${ }^{14,16-19}$ and the combined data of the adult subgroup suggested that the epidural butorphanol was more effective than control (RR 0.22; $95 \%$ CI 0.09 to 0.52 ).

Intravenous butorphanol was administered in three trials, but the heterogeneity test showed that the data were not homogeneous $(P<0.1)$. One possible cause was the route of butorphanol in one trial, i.e., an intravenous bolus, which differed from the others. The estimation performed after this trial was excluded and a random effects model was used. The difference was significant (RR 0.22 ; $95 \%$ CI 0.10 to 0.45 ) (Fig. 3). 
Table 1 Characteristics of the selected randomized controlled trials

\begin{tabular}{|c|c|c|c|}
\hline Reference & Surgery & Comparison ()$=$ number of analyzed patients & $\begin{array}{l}\text { Observation } \\
\text { period }\end{array}$ \\
\hline Yao et al. ${ }^{12}$ & Cesarean delivery & $\begin{array}{l}\text { 1. morphine } 2 \mathrm{mg} \text { epid }+ \text { placebo iv (20) } \\
\text { 2. morphine } 2 \mathrm{mg} \text { epid }+ \text { butorphanol } 160 \mu \mathrm{g} \cdot \mathrm{hr}^{-1} i v(20) \\
\text { 3. morphine } 2 \mathrm{mg} \text { epid }+ \text { butorphanol } 240 \mu \mathrm{g} \cdot \mathrm{hr}^{-1} i v(20) \\
\text { 4. morphine } 2 \mathrm{mg} \text { epid }+ \text { butorphanol } 280 \mu \mathrm{g} \cdot \mathrm{hr}^{-1} i v(20)\end{array}$ & $48 \mathrm{hr}$ \\
\hline $\mathrm{Wu}$ et al. ${ }^{13}$ & Cesarean delivery & $\begin{array}{l}\text { 1. morphine } 0.1 \mathrm{mg} \text { i.t. }+ \text { placebo } i v(45) \\
\text { 2. morphine } 0.1 \mathrm{mg} \text { i.t. }+ \text { butorphanol }\left(1 \mathrm{mg}+200 \mu \mathrm{g} \cdot \mathrm{hr}^{-1}\right) i v \text { (46) }\end{array}$ & $24 \mathrm{hr}$ \\
\hline $\mathrm{Wu}$ et al. ${ }^{14}$ & $\begin{array}{l}\text { Radical resection of rectal } \\
\text { carcinoma }\end{array}$ & $\begin{array}{l}\text { 1. morphine } 2 \mathrm{mg}+\text { placebo epid (30) } \\
\text { 2. morphine } 2 \mathrm{mg}+\text { butorphanol } 1 \mathrm{mg} \text { epid (30) }\end{array}$ & $48 \mathrm{hr}$ \\
\hline Yu et al. ${ }^{15}$ & Not specified & $\begin{array}{l}\text { 1. morphine } 20 \mu \mathrm{g} \cdot \mathrm{kg}^{-1} \cdot \mathrm{hr}^{-1} \text { i.h. (30) } \\
\text { 2. morphine } 20 \mu \mathrm{g} \cdot \mathrm{kg}^{-1} \cdot \mathrm{hr}^{-1}+\text { butorphanol } 10 \mu \mathrm{g} \cdot \mathrm{kg}^{-1} \cdot \mathrm{hr}^{-1} \text { i.h. (30) }\end{array}$ & $48 \mathrm{hr}$ \\
\hline Xiao et al. ${ }^{16}$ & Cesarean delivery & $\begin{array}{l}\text { 1. morphine } 2 \mathrm{mg}+120 \mu \mathrm{g} \cdot \mathrm{hr}^{-1} \text { epid (30) } \\
\text { 2. morphine }\left(2 \mathrm{mg}+120 \mu \mathrm{g} \cdot \mathrm{hr}^{-1}\right)+\text { butorphanol }\left(0.5 \mathrm{mg}+30 \mu \mathrm{g} \cdot \mathrm{hr}^{-1}\right) \text { epid } \\
\text { (30) }\end{array}$ & $48 \mathrm{hr}$ \\
\hline Yi et al. ${ }^{17}$ & Hysterectomy & $\begin{array}{l}\text { 1. morphine } 2 \mathrm{mg}+\text { placebo epid }(25) \\
\text { 2. morphine } 2 \mathrm{mg}+\text { butorphanol } 1 \mathrm{mg} \text { epid }(25)\end{array}$ & Not specified \\
\hline $\begin{array}{l}\text { Yokoyama } \\
\text { et al. }{ }^{18}\end{array}$ & Abdominal surgery & $\begin{array}{l}\text { 1. morphine } 3.3 \mathrm{mg} \cdot \mathrm{d}^{-1} \text { epid (20) } \\
\text { 2. morphine } 3.3 \mathrm{mg} \cdot \mathrm{d}^{-1}+\text { butorphanol } 2 \mathrm{mg} \cdot \mathrm{d}^{-1} \text { epid (20) }\end{array}$ & $75 \mathrm{hr}$ \\
\hline Ding et al. ${ }^{19}$ & Cesarean delivery & $\begin{array}{l}\text { 1. morphine } 2 \mathrm{mg} \text { epid (20) } \\
\text { 2. morphine } 2 \mathrm{mg}+\text { butorphanol } 2 \mathrm{mg} \text { epid (20) }\end{array}$ & $48 \mathrm{hr}$ \\
\hline Sakai et al. ${ }^{20}$ & Hysterectomy & $\begin{array}{l}\text { 1. morphine } 0.1 \mathrm{mg} \text { i.t. }+ \text { placebo } i v(10) \\
\text { 2. morphine } 0.1 \mathrm{mg} \text { i.t. }+ \text { butorphanol } 2 \mathrm{mg} i v(10)\end{array}$ & $24 \mathrm{hr}$ \\
\hline Gunter et al..$^{21}$ & NA & $\begin{array}{l}\text { 1. morphine } 50 \mu \mathrm{g} \cdot \mathrm{kg}^{-1}+6 \mu \mathrm{g} \cdot \mathrm{kg}^{-1} \cdot \mathrm{hr}^{-1} \text { epid (18) } \\
\text { 2. morphine }\left(50 \mu \mathrm{g} \cdot \mathrm{kg}^{-1}+6 \mu \mathrm{g} \cdot \mathrm{kg}^{-1} \cdot \mathrm{hr}^{-1}\right)+\text { butorphanol } \\
\left(10 \mu \mathrm{g} \cdot \mathrm{kg}^{-1}+1.2 \mu \mathrm{g} \cdot \mathrm{kg}^{-1} \cdot \mathrm{hr}^{-1}\right) \text { epid }(28)\end{array}$ & $24 \mathrm{~h}$ \\
\hline $\begin{array}{l}\text { Lawhorn } \\
\text { et } a l .^{22}\end{array}$ & $\begin{array}{l}\text { Spinal, abdominal or } \\
\text { thoracic }\end{array}$ & $\begin{array}{l}\text { 1. morphine } 80 \mu \mathrm{g} \cdot \mathrm{kg}^{-1} \text { epid (10) } \\
\text { 2. morphine } 80 \mu \mathrm{g} \cdot \mathrm{kg}^{-1}+\text { butorphanol } 40 \mu \mathrm{g} \cdot \mathrm{kg}^{-1} \text { epid (10) }\end{array}$ & $24 \mathrm{hr}$ \\
\hline $\begin{array}{l}\text { Lawhorn } \\
\text { et } a l .^{23}\end{array}$ & Dorsal rhizotomy & $\begin{array}{l}\text { 1. morphine } 80 \mu \mathrm{g} \cdot \mathrm{kg}^{-1} \text { epid (7) } \\
\text { 2. morphine } 80 \mu \mathrm{g} \cdot \mathrm{kg}^{-1}+\text { butorphanol } 40 \mu \mathrm{g} \cdot \mathrm{kg}^{-1} \text { epid (7) }\end{array}$ & $72 \mathrm{hr}$ \\
\hline Bailey et al. ${ }^{24}$ & $\begin{array}{l}\text { Abdominal or thoracic } \\
\text { surgery }\end{array}$ & $\begin{array}{l}\text { 1. morphine } 60 \mu \mathrm{g} \cdot \mathrm{kg}^{-1} \text { epid (20) } \\
\text { 2. morphine } 60 \mu \mathrm{g} \cdot \mathrm{kg}^{-1} \text { epid }+ \text { butorphanol } 30 \mu \mathrm{g} \cdot \mathrm{kg}^{-1} \text { epid (20) } \\
\text { 3. morphine } 60 \mu \mathrm{g} \cdot \mathrm{kg}^{-1} \text { epid }+ \text { butorphanol } 30 \mu \mathrm{g} \cdot \mathrm{kg}^{-1} i v(20)\end{array}$ & $24 \mathrm{hr}$ \\
\hline $\begin{array}{l}\text { Gambling } \\
\text { et al. }\end{array}$ & Cesarean delivery & $\begin{array}{l}\text { 1. morphine } 3 \mathrm{mg}+\text { placebo epid (23) } \\
\text { 2. morphine } 3 \mathrm{mg}+\text { butorphanol } 1 \mathrm{mg} \text { epid (10) } \\
\text { 3. morphine } 3 \mathrm{mg}+\text { butorphanol } 2 \mathrm{mg} \text { epid (21) } \\
\text { 4. morphine } 3 \mathrm{mg}+\text { butorphanol } 3 \mathrm{mg} \text { epid (17) }\end{array}$ & $24 \mathrm{hr}$ \\
\hline $\begin{array}{l}\text { Wittels } \\
\text { et } a l .^{26}\end{array}$ & Cesarean delivery & $\begin{array}{l}\text { 1. morphine } 4 \mathrm{mg} \text { epid (25) } \\
\text { 2. morphine } 4 \mathrm{mg}+\text { butorphanol } 4 \mathrm{mg} \text { epid (28) }\end{array}$ & $24 \mathrm{hr}$ \\
\hline $\begin{array}{l}\text { Lawhorn } \\
\text { et } a l .^{27}\end{array}$ & Cesarean delivery & $\begin{array}{l}\text { 1. morphine } 4 \mathrm{mg} \text { epid (10) } \\
\text { 2. morphine } 4 \mathrm{mg}+\text { butorphanol } 1 \mathrm{mg} \text { epid (10) } \\
\text { 3. morphine } 4 \mathrm{mg}+\text { butorphanol } 3 \mathrm{mg} \text { epid (10) }\end{array}$ & $24 \mathrm{hr}$ \\
\hline
\end{tabular}

epid = epidural; i.t. = intrathecal; i.h. = subcutaneous; $\mathrm{NA}=$ data not available

Subcutaneous butorphanol was tested in only one trial ${ }^{15}$ and was reported more effective than placebo in decreasing the incidence of pruritus ( $13.3 \%$ vs $36.7 \%$, respectively).

A funnel plot and an Egger's test were performed to evaluate the publication bias in all trials investigating the incidence of pruritus. The graphical asymmetry of the funnel plot and the $P$ value $(P<0.05)$ of the Egger's test indicated a potential for publication bias (Fig. 4). Nevertheless, the fail-safe number for the overall effect of butorphanol on the incidence of pruritus was 202, which indicated that 202 additional non-significant or unpublished studies were needed for the RR to be equal 


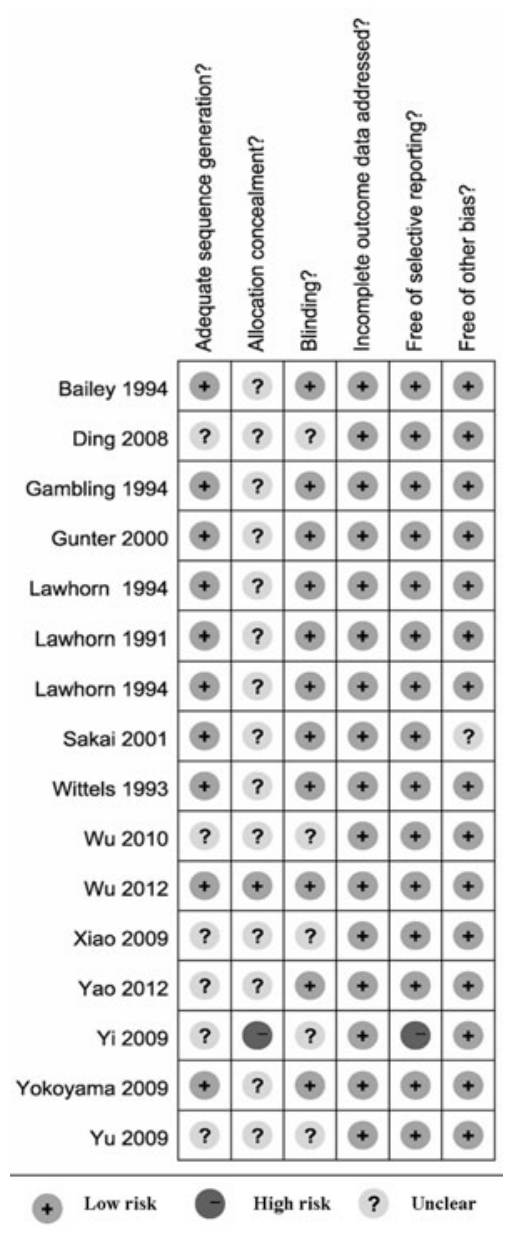

Fig. 2 Summary of the risk of bias in the included studies

to 1 . This implies that the result of our meta-analysis was reasonably stable. ${ }^{28,29}$

The request for rescue treatment of pruritus

The effect of epidural butorphanol on the number of patients requesting rescue treatment for pruritus was reported in five studies. ${ }^{21,24-27}$ Treatment was requested by $27.1 \%$ (39 in 144) of the patients in the epidural butorphanol group and by $46.7 \%$ (45 in 96) of the patients in the control group. Thus, prophylactic administration of epidural butorphanol significantly decreased the number of patients requesting curative treatment for pruritus (RR 0.57 ; $95 \%$ CI 0.41 to 0.81 ) (Fig. 5).

The effect of a single injection of intravenous butorphanol on the number of patients requesting rescue treatment for pruritus was evaluated in one trial. ${ }^{24}$ The data showed that a single injection of intravenous butorphanol was not effective in decreasing the number of patients requesting rescue treatment for pruritus when compared with placebo ( $45 \%$ vs $40 \%$, respectively).
Postoperative pain intensity

Data on VAS pain scores at different postoperative time points were reported in nine trials. ${ }^{12-15,17,19,20,26,27}$ Data on pain scores at four, eight, 12, 24, and $48 \mathrm{hr}$ following the operation were combined because several studies reported VAS pain scores at each of the above time points. At four, eight, and $12 \mathrm{hr}$, butorphanol decreased pain intensity with SMD $-0.29(95 \% \mathrm{CI}-0.52$ to -0.05$),-0.30(95 \% \mathrm{CI}$ -0.56 to -0.04$)$, and -0.23 (95\% CI -0.46 to -0.01$)$, respectively. At 24 and $48 \mathrm{hr}$, heterogeneity existed among trials (Fig. 6). We excluded one trial ${ }^{12}$ which strongly suggested that adding butorphanol to morphine decreased pain intensity because this trial potentially biased the results. When performed again, the results of the reestimation showed SMDs of -0.60 (95\% CI -0.99 to $-0.21)$ at $24 \mathrm{hr}$ and $-0.11(95 \% \mathrm{CI}-0.38$ to 0.16$)$ at $48 \mathrm{hr}$.

\section{Prevention of PONV}

The effect of intravenous butorphanol on PONV was reported in three trials. The combined data indicated a nonsignificant lower incidence of PONV in the intravenous butorphanol groups (RR $0.77 ; 95 \%$ CI 0.24 to 2.50 ) (Fig 7).

The effect of epidural butorphanol on PONV was reported in eight trials. The combined data showed a significant effect on preventing nausea and vomiting (RR $0.35 ; 95 \%$ CI 0.19 to 0.66 ) (Fig 7).

Respiratory depression, dizziness, and somnolence

Ten trials reported the incidence of respiratory depression with morphine or morphine combined with butorphanol. Definitions of respiratory depression were taken as reported in the original trials. Using these criteria, 9 of $244(3.4 \%)$ patients with morphine/butorphanol combination had respiratory depression compared with 11 of $210(5.2 \%)$ with morphine alone. No significant difference was found (RR $0.71 ; 95 \%$ CI 0.31 to 1.63 ) (Table 2).

Four trials reported the incidence of somnolence. In one trial $^{24}$ the number of patients experiencing somnolence was unusually high (47\% and $39 \%$ of 20 patients in each group) and was excluded. In the other three trials, four of $68(5.9 \%)$ patients with morphine/butorphanol combination and five of $55(9.1 \%)$ patients with morphine alone experienced somnolence. No significant difference was found (RR $0.71 ; 95 \%$ CI 0.22 to 2.37) (Table 2).

Five trials reported the incidence of dizziness with intravenous or epidural butorphanol combined with morphine. In these trials, 20 of $175(11.4 \%)$ patients with morphine/butorphanol combination and 13 of $136(9.6 \%)$ patients with morphine alone suffered dizziness. No 


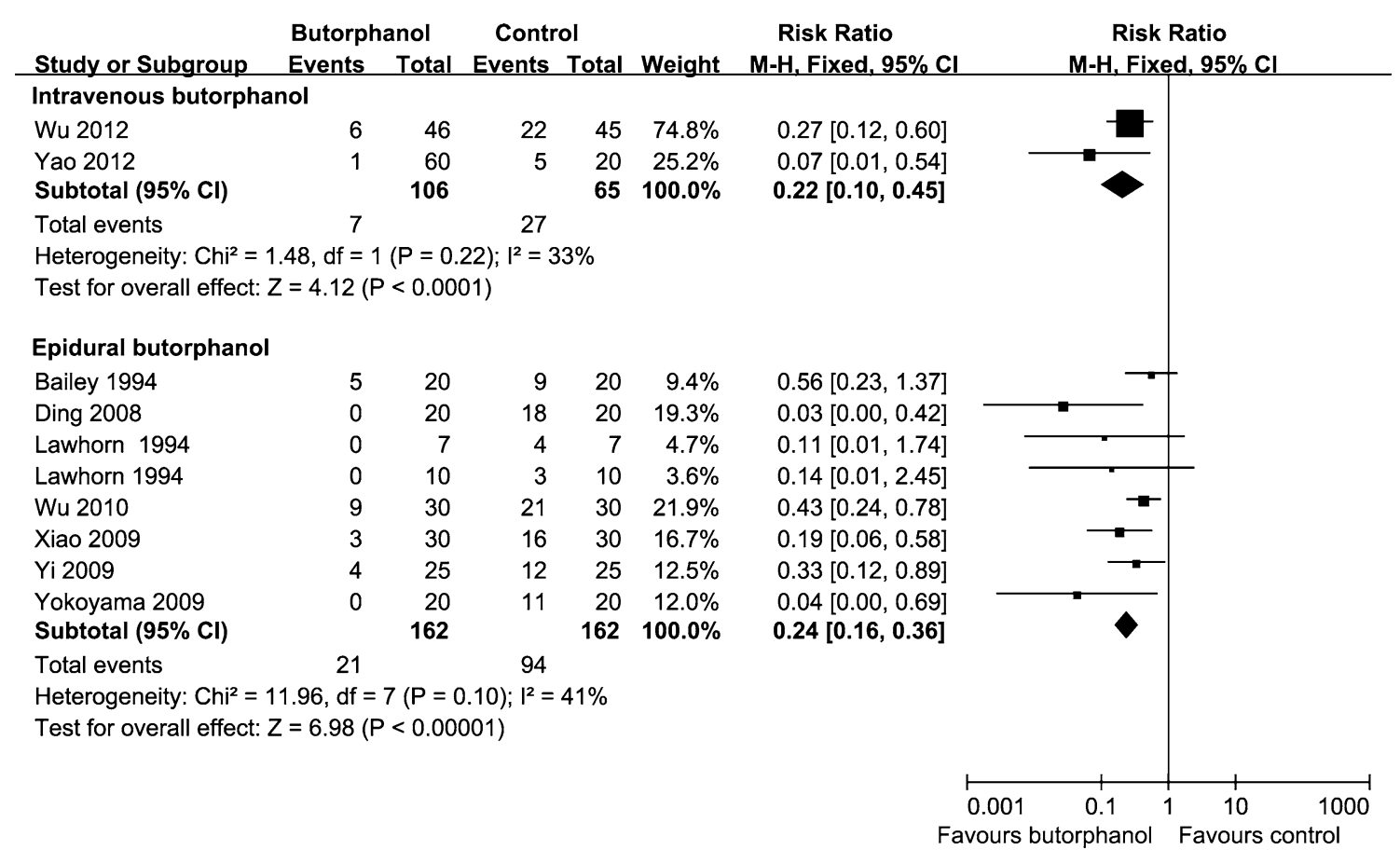

Fig. 3 Effect of butorphanol on the incidence of pruritus. Symbols are relative risks with 95\% CI (confidence intervals). Black diamond $=$ combined estimate. The vertical lines represent unity (i.e., no effect)

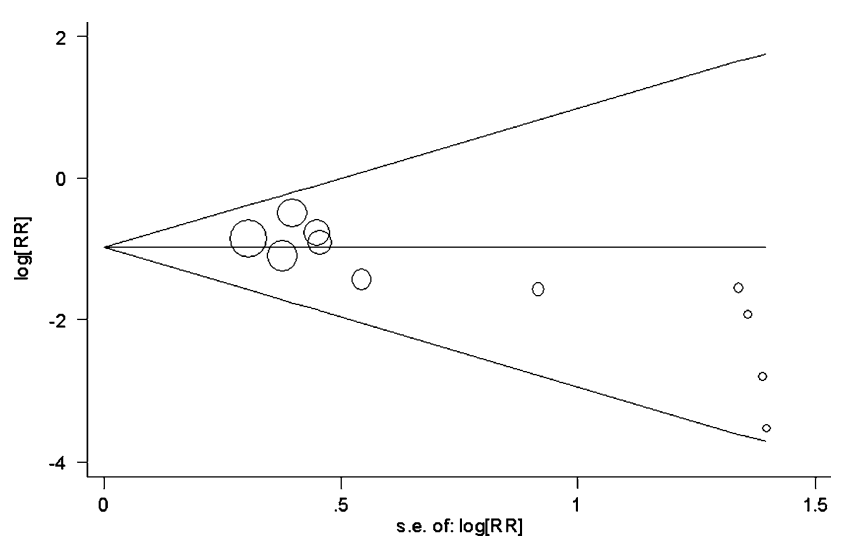

Fig. 4 Funnel plot with 95\% CI (confidence intervals) for all trials investigating the incidence of pruritus ( $P$ value of Egger's test was $<0.05) . \mathrm{RR}=$ relative risk

significant difference was found (RR 2.45; 95\% CI 0.35 to 17.14) (Table 2).

Quality of this review

We used the AMSTAR quality criteria to assess the strengths of this review and meta-analysis. In our review, the excluded studies were not provided and the conflict of interest was not stated. As a result, this review met nine of the 11 AMSTAR quality criteria, which indicated high quality. ${ }^{30}$

\section{Discussion}

Pruritus is an uncomfortable sensation on the skin that often makes patients restless. Currently, the mechanism underlying morphine-related pruritus remains uncertain, but morphine-induced pruritus is considered mediated by the $\mu$-opioid receptors ${ }^{31}$ and the $\kappa$-opioid receptors. ${ }^{32,33}$ Accordingly, administration of butorphanol (a partial $\mu$ - opioid receptor antagonist and $\kappa$-opioid receptor agonist) with morphine ( $\mu$ - and $\kappa$-receptor agonist) would be expected to maintain analgesia ( $\mu$ - and $\kappa$-receptors) while reducing pruritus. ${ }^{21}$ Butorphanol has been used to treat intractable pruritus based on its potential anti-pruritus effect, ${ }^{5}$ but debate on the efficacy of prophylactic butorphanol on morphine-induced pruritus still exists. This systematic review was designed to evaluate the impact of butorphanol on morphine-induced pruritus in perioperative analgesia. The results of this analysis indicated that prophylactic administration of epidural and continuous intravenous butorphanol significantly decreased the incidence of pruritus associated with morphine.

There were two earlier systematic reviews ${ }^{34,35}$ on the pharmacological intervention of opioid-induced pruritus, but both did not focus on butorphanol and studies of pediatric patients were excluded. In our systematic review, four trials in children were available, and the combined data from three trials reporting the occurrence of pruritus showed that butorphanol could significantly reduce morphine-induced pruritus. 


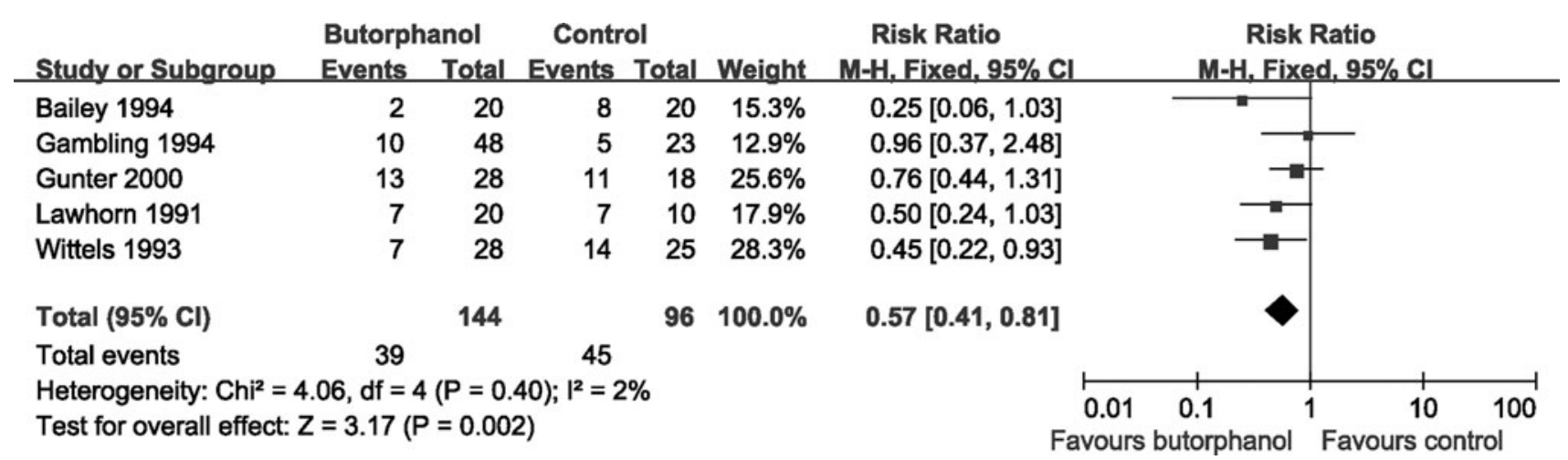

Fig. 5 Effect of epidural butorphanol on the number of patients requesting rescue treatment for pruritus. Symbols are relative risks with $95 \%$ CI (confidence intervals). Black diamond $=$ combined estimate. The vertical lines represent unity (i.e., no effect)

The number of patients requesting rescue treatment for pruritus was selected to assess the efficacy of butorphanol in preventing pruritus, and this was reported in five trials. Four of the five trials showed negative results, while only one trial concluded that epidural butorphanol was effective. Nevertheless, in our meta-analysis, we pooled all data of patients to raise the evidence level, which resulted in a more precise and credible conclusion to show the efficacy of epidural butorphanol.

In addition, continuous infusion and single injection of intravenous butorphanol differed in the effects they had on preventing pruritus. For continuous intravenous infusion of butorphanol, the combined data of two trials ${ }^{12,13}$ suggested that it had a significant effect on preventing pruritus. On the other hand, when intravenous butorphanol was administered by single injection, the incidence of pruritus, ${ }^{24}$ the number of patients requesting treatment for pruritus, ${ }^{24}$ and the VAS scores for pruritus ${ }^{20,24}$ did not decrease when compared with control. The distinct effects in preventing pruritus might result from the different pharmacokinetics of the two regimens of butorphanol. ${ }^{36}$

Small-size and low-quality trials often overestimate the benefits of treatment; $; 7$ therefore, sensitivity analysis was performed in our review. The effect of epidural butorphanol on the incidence of pruritus was re-analyzed after excluding one study with a small group size and one study with a high risk of bias. The combined data still showed that epidural butorphanol could decrease the incidence of pruritus, which indicated that our result was stable. The fail-safe number, a value of 202 , was also used to evaluate the reliability of our result, and it indicated that the meta-analysis would require a large number of nonsignificant associations to negate the significance. ${ }^{29}$

In our review, we also investigated whether butorphanol decreases the analgesic efficacy of morphine while improving pruritus. The VAS pain score was used to evaluate the efficacy of postoperative analgesia, and results indicated that a butorphanol-morphine combination could decrease postoperative pain intensity at four to $24 \mathrm{hr}$ and did not worsen postoperative pain at $48 \mathrm{hr}$. This effect is attributed to the partial agonistic activity of butorphanol on $\mu_{1}$ - and $\kappa$-receptors that are correlated with pain. ${ }^{21}$

Our meta-analysis also suggests that epidural, but not intravenous butorphanol, provided a significant decrease in the incidence of PONV when compared with placebo or control. Earlier experiments ${ }^{38}$ showed that elements involved in the mechanism of nausea and vomiting were not considered equally sensitive to intravenous and epidural opioid receptor antagonists, which could explain the difference in effectiveness between the two routes of administering butorphanol.

Moreover, butorphanol administered with morphine did not increase the incidence of other potential side effects. Clinically, respiratory depression is one of the most feared side effects of opioids. The addition of butorphanol to morphine in the range of doses tested in these trials did not increase the incidence of respiratory depression. Intravenous butorphanol increased the Ramsay sedation score at $24 \mathrm{hr}^{13}$ and the incidence of somnolence, ${ }^{26}$ but epidural butorphanol did not cause any difference in the incidence of somnolence. Dizziness is a common side effect of butorphanol, ${ }^{39}$ but our synthetic result indicated that butorphanol did not increase the incidence of dizziness.

Our quality assessment based on AMSTAR criteria indicated high-quality strength in this systematic review. Nevertheless, our review has some limitations. First, we found evidence of publication bias using Egger's test and a funnel plot. Publication bias tends to occur when "positive" studies are more likely to be published in English, although all published studies and abstracts were included and there was no language restriction in this systematic review. Even so, the fail-safe number was 202 , which indicated the stability of our results. Second, the included studies in our review have different patient populations, surgical procedures, and lengths of follow-up, which caused clinical heterogeneity when meta-analysis was performed. Third, 


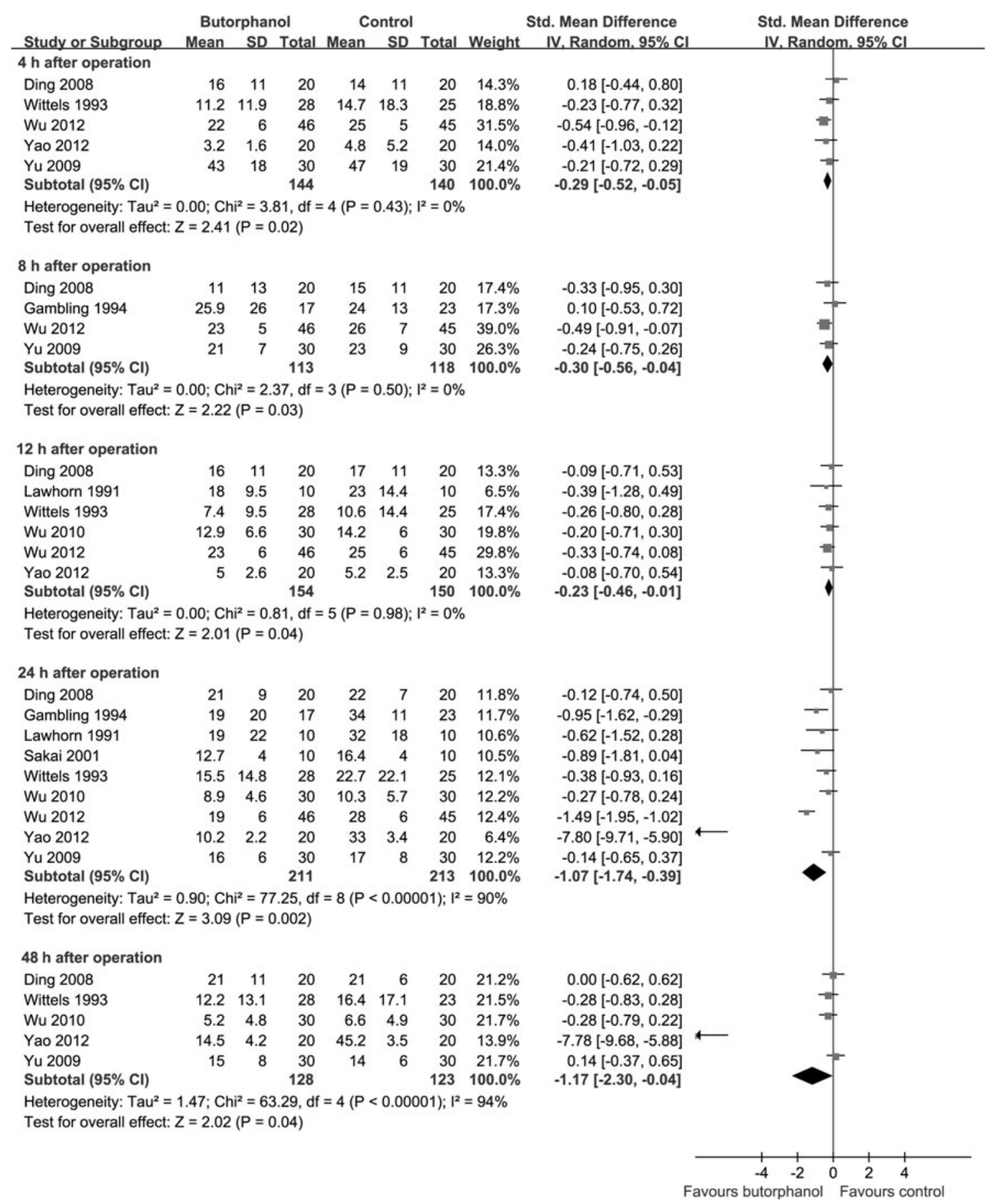

Fig. 6 Effect of butorphanol on postoperative pain. Symbols are standardized mean difference with 95\% CI (confidence intervals). Black diamond $=$ combined estimate. The vertical lines represent unity (i.e., no effect)

there might be a selection bias in our analyses of other side effects apart from pruritus; for example, we analyzed the data of postoperative pain, PONV, respiratory depression, dizziness, and somnolence from trials that were systematically searched for a different purpose. Lastly, since most studies included in our review were of small size, they potentially overestimate therapeutic effects and underrate relevant side effects.
Our systematic review summarizes the current scientific knowledge on the role of butorphanol to prevent postoperative morphine-induced pruritus. This review also raises recommendations for further research, for instance, more trials are needed to evaluate the effect of butorphanol on established pruritus, as there are few studies on this subject. ${ }^{5,40}$ This review suggests that intravenous and epidural butorphanol may differ in their effects on preventing pruritus, but there was 


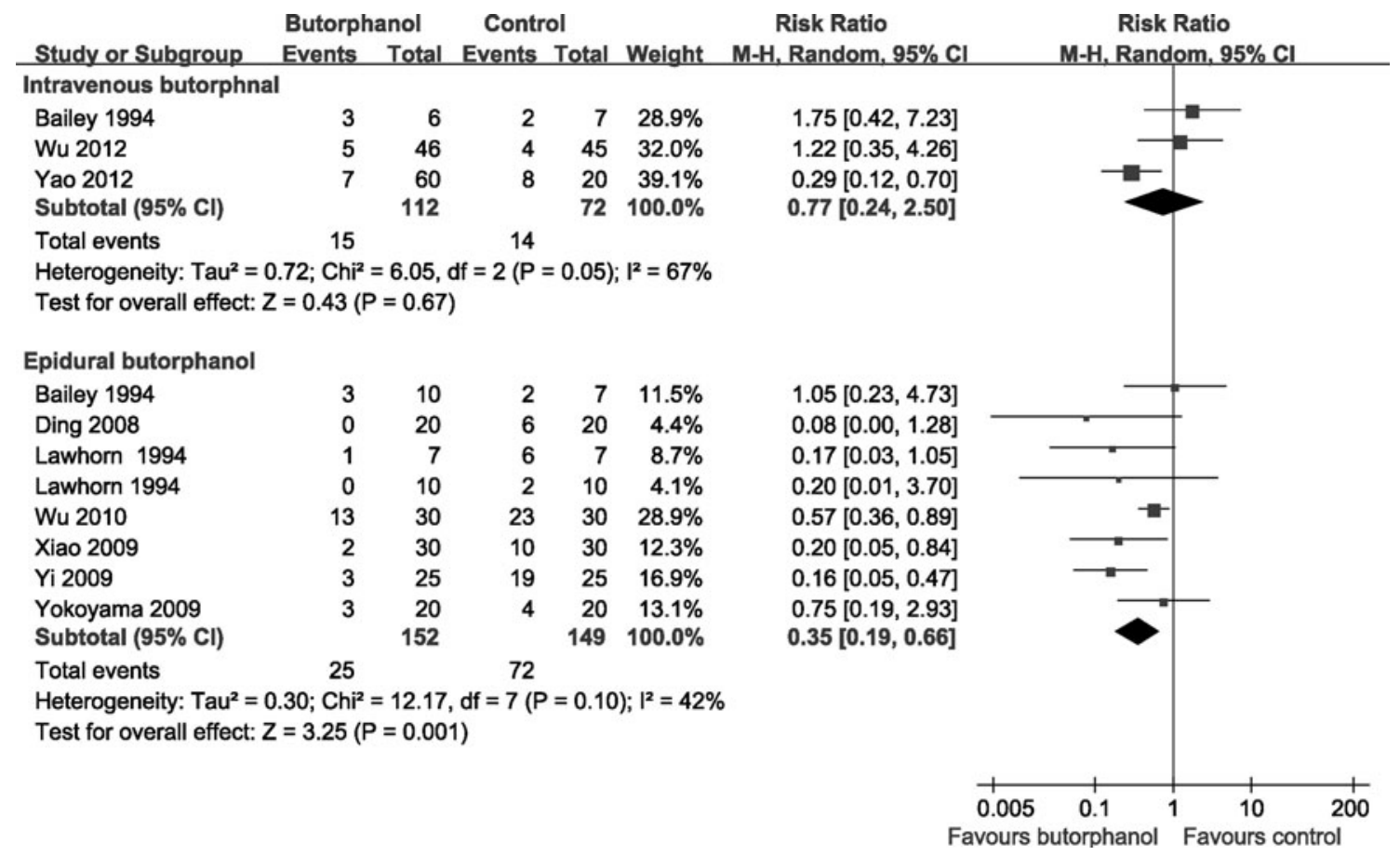

Fig. 7 Effect of butorphanol on preventing nausea and vomiting. Symbols are relative risks with 95\% CI (confidence intervals). Black diamond $=$ combined estimate. The vertical lines represent unity (i.e., no effect)

Table 2 Incidence of various side effects with butorphanol $v s$ placebo

\begin{tabular}{|c|c|c|c|c|c|}
\hline \multirow[t]{2}{*}{ Side effects } & \multirow[t]{2}{*}{ Number of studies } & \multicolumn{2}{|c|}{ Number pruritus /total number of patients } & \multirow[t]{2}{*}{ Relative risk $(95 \% \mathrm{CI})$} & \multirow[t]{2}{*}{ References } \\
\hline & & Butorphanol & Control & & \\
\hline Respiratory depression & 10 & $9 / 244$ & $11 / 210$ & $0.71(0.31$ to 1.63$)$ & $13,16-18,21-24,26,27$ \\
\hline Somnolence & 3 & $4 / 68$ & $5 / 55$ & $0.71(0.22$ to 2.37$)$ & $19,26,27$ \\
\hline Dizziness & 5 & $20 / 175$ & $13 / 136$ & 2.45 (0.35 to 17.14$)$ & $13,15-18$ \\
\hline
\end{tabular}

$\mathrm{CI}=$ confidence intervals

only one trial $^{24}$ in which a head-to-head comparison was performed between intravenous and epidural butorphanol. In addition, more high-quality randomized double-blind trials with a reasonable number of patients and a proper length of follow-up are needed to provide data on the efficacy, doseresponsiveness, and optimal routes of administering butorphanol to prevent pruritus and other side effects.

In conclusion, the current systematic review shows the potential benefits of using butorphanol to prevent morphine-induced pruritus and decrease pain intensity and PONV without increasing other side effects.

\section{References}

1. Chaney MA. Side effects of intrathecal and epidural opioids. Can J Anaesth 1995; 42: 891-903.

2. Szarvas $S$, Harmon D, Murphy D. Neuraxial opioid-induced pruritus: a review. J Clin Anesth 2003; 15: 234-9.
3. Ganesh A, Maxwell LG. Pathophysiology and management of opioid-induced pruritus. Drugs 2007; 67: 2323-33.

4. Jaw SP, Hoskins B, Ho IK. Opioid antagonists and butorphanol dependence. Pharmacol Biochem Behav 1993; 44: 497-500.

5. Dawn AG, Yosipovitch G. Butorphanol for treatment of intractable pruritus. J Am Acad Dermatol 2006; 54: 527-31.

6. Thakur BP, Sharma SK, Sharma A, Kumar A. Clinical evaluation of detomidine-butorphanol-guaifenesin-ketamine as short term TIVA in Spiti ponies. Pak J Biol Sci 2011; 14: 647-52.

7. Szabova A, Sadhasivam S, Wang Y, Nick TG, Goldschneider K. Comparison of postoperative analgesia with epidural butorphanol/ bupivacaine versus fentanyl/bupivacaine following pediatric urological procedures. J Opioid Manag 2010; 6: 401-7.

8. Nelson KE, Eisenach JC. Intravenous butorphanol, meperidine, and their combination relieve pain and distress in women in labor. Anesthesiology 2005; 102: 1008-13.

9. Liberati A, Altman DG, Tetzlaff $J$, et al. The PRISMA statement for reporting systematic reviews and meta-analyses of studies that evaluate healthcare interventions: explanation and elaboration. BMJ 2009; 339: b2700.

10. Higgins JP, Green S. Cochrane Handbook for Systematic Reviews of Interventions: Cochrane Book Series. John Wiley \& Sons, Inc. Online Library; The Cochrane Collaboration 2008. 
Available from URL: http://onlinelibrary.wiley.com/book/10. 1002/9780470712184 (accessed May 2013).

11. Shea BJ, Grimshaw JM, Wells GA, et al. Development of AMSTAR: a measurement tool to assess the methodological quality of systematic reviews. BMC Med Res Methodol 2007; 7: 10.

12. Yao X, Liu Y, Lei L. Effect of intravenous butorphanol on the side effects associated with epidural morphine in postoperative analgesia. J Clin Anesthesiol 2012; 28: 58-9.

13. Wu Z, Kong $M$, Wang $N$, Finlayson RJ, De Tran $Q H$. Intravenous butorphanol administration reduces intrathecal morphine-induced pruritus after cesarean delivery: a randomized, double-blind, placebo-controlled study. J Anesth 2012; 26: 752-7.

14. Wu X, Zhu M, Yin Y, Cao Y. Butorphanol plus ondansetron as prophylactic antiemetic and antipruritic therapy in patients receiving intrathecal morphine for radical resection of rectal carcinoma. Chinese Journal of Clinical Medicine 2010; 17: 405-7.

15. Yu K, Li Y, Xu S, Zhong H, Xiao Y, Peng C. Application of postoperative patient-controlled subcutaneous analgesia with butorphanol and morphine. Journal of Yunyang Medical College 2009; 28: 579-81.

16. Xiao X, Yang L, Zhu $Y$. The clinic observation of butorphanol for prevention of itching in postoperative epidural analgesia with morphine after caesarean section. China Prac Med 2009; 4: 49-51.

17. $Y i \quad B$. Effect of morphine combined with butorphanol for postoperative analgesia. Hebei Medcine 2009; 15: 591-3.

18. Yokoyama Y, Yokoyama T, Nagao Y, Nakagawa T, Magaribuchi $T$. Treatment of epidural morphine induced pruritus with butorphanol (Japanese). Masui 2009; 58: 178-82.

19. Ding J, Zhang X, Qiu G, Feng J. Morphine combined with butorphanol for epidural analgesia after cesarean section. Herald of Medicine 2008; 27: 305-6.

20. Sakai T, Fukano T, Sumikawa K. IV butorphanol reduces analgesia but not pruritus or nausea associated with intrathecal morphine. Can J Anesth 2001; 48: 831-2.

21. Gunter JB, McAuliffe J, Gregg T, Weidner N, Varughese AM, Sweeney DM. Continuous epidural butorphanol relieves pruritus associated with epidural morphine infusions in children. Paediatr Anaesth 2000; 10: 167-72.

22. Lawhorn CD, Brown RE Jr. Epidural morphine with butorphanol in pediatric patients. J Clin Anesth 1994; 6: 91-4.

23. Lawhorn $C D$, Boop $F$, Brown $R$, Andelman P. Epidural pain management in the postrhizotomy patient. Pediatr Neurosurg 1994; 20: 198-202.

24. Bailey AG, Valley RD, Freid EB, Calhoun P. Epidural morphine combined with epidural or intravenous butorphanol for postoperative analgesia in pediatric patients. Anesth Analg 1994; 79: 340-4.

25. Gambling DR, Howell $P$, Huber $C$, Kozak S. Epidural butorphanol does not reduce side effects from epidural morphine after cesarean birth. Anesth Analg 1994; 78: 1099-104.
26. Wittels B, Glosten B, Faure EA, et al. Opioid antagonist adjuncts to epidural morphine for postcesarean analgesia: maternal outcomes. Anesth Analg 1993; 77: 925-32.

27. Lawhorn CD, McNitt JD, Fibuch EE, Joyce JT, Leadley RJ Jr. Epidural morphine with butorphanol for postoperative analgesia after cesarean delivery. Anesth Analg 1991; 72: 53-7.

28. Richardson S, Shaffer JA, Falzon L, Krupka D, Davidson KW, Edmondson D. Meta-analysis of perceived stress and its association with incident coronary heart disease. Am J Cardiol 2012; 110: 1711-6.

29. Chida Y, Steptoe A. Greater cardiovascular responses to laboratory mental stress are associated with poor subsequent cardiovascular risk status: a meta-analysis of prospective evidence. Hypertension 2010; 55: 1026-32.

30. Malik VS, Hu FB. Sugar-sweetened beverages and health: where does the evidence stand? Am J Clin Nutr 2011; 94: 1161-2.

31. Waxler B, Dadabhoy ZP, Stojiljkovic L, Rabito SF. Primer of postoperative pruritus for anesthesiologists. Anesthesiology 2005; 103: 168-78.

32. Ko MC, Lee H, Song MS, et al. Activation of kappa-opioid receptors inhibits pruritus evoked by subcutaneous or intrathecal administration of morphine in monkeys. J Pharmacol Exp Ther 2003; 305: 173-9.

33. Kumagai H, Ebata T, Takamori K, Muramatsu T, Nakamoto H, Suzuki $H$. Effect of a novel kappa-receptor agonist, nalfurafine hydrochloride, on severe itch in 337 haemodialysis patients: a Phase III, randomized, double-blind, placebo-controlled study. Nephrol Dial Transplant 2010; 25: 1251-7.

34. Kjellberg F, Tramer MR. Pharmacological control of opioidinduced pruritus: a quantitative systematic review of randomized trials. Eur J Anaesthesiol 2001; 18: 346-57.

35. Bonnet MP, Marret E, Josserand J, Mercier FJ. Effect of prophylactic 5-HT3 receptor antagonists on pruritus induced by neuraxial opioids: a quantitative systematic review. Br J Anaesth 2008; 101: 311-9.

36. Sellon DC, Monroe VL, Roberts MC, Papich MG. Pharmacokinetics and adverse effects of butorphanol administered by single intravenous injection or continuous intravenous infusion in horses. Am J Vet Res 2001; 62: 183-9.

37. Moher D, Pham B, Jones A, et al. Does quality of reports of randomised trials affect estimates of intervention efficacy reported in meta-analyses? Lancet 1998; 352: 609-13.

38. Costello DJ, Borison HL. Naloxone antagonizes narcotic self blockade of emesis in the cat. J Pharmacol Exp Ther 1977; 203: 222-30.

39. Olsen JC, McGrath NA, Schwarz DG, Cutcliffe BJ, Stern JL. A double-blind randomized clinical trial evaluating the analgesic efficacy of ketorolac versus butorphanol for patients with suspected biliary colic in the emergency department. Acad Emerg Med 2008; 15: 718-22.

40. Dunteman E, Karanikolas M, Filos KS. Transnasal butorphanol for the treatment of opioid-induced pruritus unresponsive to antihistamines. J Pain Symptom Manage 1996; 12: 255-60. 